\title{
Article \\ Study on Mechanical and Shrinkage Properties of High Belite Sulphoaluminate Cement-Based Green Recycled Aggregate Concrete
}

\author{
Zexin Yu ${ }^{1,2} \oplus$, Yuanxin Guo ${ }^{1}$, Gongbing Yue ${ }^{1}$, Zhenwen Hu ${ }^{1}$, Chao Liu ${ }^{2}$, Qiuyi Li ${ }^{1, *}$ and Liang Wang ${ }^{1, *}$ \\ 1 School of Architectural Engineering, Qingdao Agricultural University, Qingdao 266109, China; \\ zexinyu666@163.com (Z.Y.); guoyuanxin@qau.edu.cn (Y.G.); yuegongbing@163.com (G.Y.); \\ 20192214693@stu.qau.edu.cn (Z.H.) \\ 2 School of Civil Engineering, Qingdao University of Technology, Qingdao 266033, China; \\ charlesLau258@outlook.com \\ * Correspondence: lqyyxn@163.com (Q.L.); jiangongwl_2019@163.com (L.W.); Tel.: +86-139-6985-9949 (Q.L.); \\ +86-152-8876-3760 (L.W.)
}

check for

updates

Citation: Yu, Z.; Guo, Y.; Yue, G.; Hu, Z.; Liu, C.; Li, Q.; Wang, L. Study on Mechanical and Shrinkage Properties of High Belite Sulphoaluminate Cement-Based Green Recycled Aggregate Concrete. Crystals 2021, 11, 1512. https://doi.org/10.3390/ cryst11121512

Academic Editors: Chongchong Qi and Dawei Wang

Received: 12 November 2021

Accepted: 2 December 2021

Published: 4 December 2021

Publisher's Note: MDPI stays neutral with regard to jurisdictional claims in published maps and institutional affiliations.

Copyright: (c) 2021 by the authors. Licensee MDPI, Basel, Switzerland. This article is an open access article distributed under the terms and conditions of the Creative Commons Attribution (CC BY) license (https:/ / creativecommons.org/licenses/by/ $4.0 /)$.

\begin{abstract}
Green recycled aggregate concrete (RAC) with high strength and low shrinkage is prepared based on recycled coarse aggregate produced by the particle-shaping and aggregate-strengthening method and green low-carbon new cement. This not only effectively alleviates the shortage of natural resources, but also improves the performance of recycled aggregate concrete, which is of great significance for multi-channel resource utilization of construction waste. In this study, three kinds of recycled coarse aggregates (RCA), including simple crushing recycled coarse aggregate (JDRCA), one-time particle-shaping recycled coarse aggregate (KL-RCA) and two-time particle-shaping recycled coarse aggregate (EKL-RCA), were prepared from the preparation technology of recycled aggregate, and high belite sulphoaluminate cement with excellent performance was used. The effects of aggregate quality, aggregate replacement ratio, and cementitious material content on mechanical properties and shrinkage properties of green recycled aggregate concrete were studied in comparison with ordinary Portland cement-based recycled aggregate concrete. The testing results show that the particle-shaping method can effectively improve the aggregate quality. The compressive strength and dry shrinkage performance of recycled aggregate concrete made of particle-shaped aggregate are only a little different from those of natural aggregate concrete, and even the performance of recycled aggregate is better than that of natural aggregate concrete under the condition of a low replacement ratio of recycled aggregate. In addition, high belite sulphoaluminate cement-based recycled aggregate concrete (HBRAC) not only has early strength and rapid hardening, but also has excellent drying shrinkage resistance, and its shrinkage rate can be reduced to more than $75 \%$ compared with ordinary Portland cement-based recycled aggregate concrete (OPRAC).
\end{abstract}

Keywords: recycled aggregate concrete; particle-shaping method; high belite sulphoaluminate cement; mechanical properties; shrinkage properties

\section{Introduction}

In recent years, the rapid development of the global economy has led to the rapid rise of the construction industry, but its rapid development inevitably faces many problems such as construction waste pollution and over-exploitation of natural aggregate. How to properly deal with these problems has become an important topic in today's social research [1-5]. With the protection of environment and the strengthening of the consciousness of social sustainable development, the application of recycled concrete has become an important development direction of construction waste recycling [6-10].

How to reuse recycled coarse aggregate (RCA) in concrete is an important subject in the research of recycled aggregate concrete (RAC), which promotes the rapid development 
of reinforced preparation technology of RCA. This technology can improve the inferior properties of RCA, such as roughness, porosity, high water absorption, and high crushing index. It treats construction waste after a series of processes and re-use it as building materials [11-15]. At present, RCA is mainly strengthened by physical and chemical methods. Physical strengthening requires grinding the RCA by various mechanical methods, and directly removes inferior parts [16-18]. Chemical strengthening consists of pre-treatment of RCA by various slurry pouring and soaking, and indirectly makes up for the inferior part [19-23]. The particle-shaping method used in this paper is a new technology that can effectively grind the old mortar and cement paste attached to the surface of RCA by using the repeated impact and mutual friction between RCAs under the high-speed movement of line speed (the speed of the fixed axis of the vertical rotating impeller in circular motion at any point of the recycled aggregate) $\geq 80 \mathrm{~m} / \mathrm{s}$ and can effectively strengthen RCA [24].

Mechanical properties are important properties in the research of recycled concrete. The mechanical properties of RAC increase with the improvement of the quality of RCA and decrease with the increase of the replacement ratio of RCA. It is an important research direction to analyze the properties of RAC from the aspects of the quality and replacement ratio of RCA [25-29]. Ismail et al. used hydrochloric acid and calcium silicate solution to strengthen recycled coarse aggregate and found that the strength of recycled concrete prepared by it was also greatly improved [30]. Limbachiya et al. studied the change of compressive strength of recycled aggregate concrete under different aggregate replacement ratios and found that when the replacement ratio is over 30\%, the compressive strength decreases obviously with the increase of the replacement ratio [31].

Because of the low elastic modulus, high porosity, and many micro-cracks of RCA, the shrinkage deformation of RAC prepared by RCA is larger than that of ordinary concrete, which brings great restrictions to the application of RAC. At present, many scholars choose high-quality RCA and add mineral admixtures and admixtures to reduce the shrinkage deformation of RAC [32-36]. Domingo et al. found that the shrinkage of concrete with 100\% recycled coarse aggregate increased by about $70 \%$ compared with ordinary concrete [37]. Kou et al.'s research on mineral admixtures found that the addition of fly ash, ground blast furnace slag, and metakaolin makes the drying shrinkage of RAC larger, while the addition of fly ash and ground slag makes the drying shrinkage of recycled concrete smaller [38]. He et al. found that the addition of shrinkage-reducing admixture can significantly reduce the shrinkage deformation of recycled concrete [39].

It is a new idea to use new cement to improve the strength of RAC and reduce the shrinkage deformation of RAC. High belite sulphoaluminate cement is a new green inorganic nonmetallic cementing material developed based on of traditional Portland cement and sulphoaluminate cement [40-45]. Compared with ordinary Portland cement, this kind of cement has a lower firing temperature and most of its raw materials are industrial solid wastes, which not only have less carbon dioxide emissions, but also reuse solid wastes based on cost saving. This outstanding feature is in line with the concept of green development of man and nature in China. In addition, cement also has the advantages of high early strength, stable development of late strength, low alkali corrosion resistance, strong drying shrinkage resistance, and good appearance of cement in comprehensive properties, which provide favorable conditions for the preparation of green RAC.

In this paper, the 45 groups of experimental proportions were designed to prepare green RAC with RCA after simple crushing and particle-shaping treatment as main raw materials and high belite sulphoaluminate cement as basic cementitious material. The effects of cementitious material content, physical quality, and the replacement ratio of aggregate on mechanical properties and drying shrinkage properties were systematically studied and compared with OPRAC to show the advantages of HBRAC. 


\section{Experimental Program}

\subsection{Raw Materials}

The 42.5R high belite sulphoaluminate cement (HBSAC) produced by China Tangshan Polar Bear Building Materials Co., Ltd. (Tangshan, China) was used in this study, which is fired from industrial solid waste, and its chemical composition and mineral composition are shown in Table 1. Ordinary Portland cement (OPC) produced by Shandong Mountain Aluminum Cement Corp., Ltd. (Qingdao, China) and its chemical composition and mineral composition are shown in Table 2. Grade II river sand produced in Pingdu, China, as a natural fine aggregate, has good gradation, and its performance index is shown in Table 3. Granite crushed stone produced in Qingdao, China, as natural coarse aggregate, has good gradation, and its performance index is shown in Table 4. The test methods of performance indexes in Tables 3 and 4 refer to the Standard for Technical requirements and Test Method of Sand and Crushed Stone for Ordinary Concrete (JGJ 52-2006, China). The recycled coarse aggregate (RCA) includes the following: simple crushing recycled coarse aggregate (JD-RCA), one-time particle-shaping recycled coarse aggregate (KL-RCA), and two-time particle-shaping recycled coarse aggregate (EKL-RCA); ordinary tap water in Qingdao, China; and the polycarboxylic acid superplasticizer with a water-reducing rate of $30 \%$, which is provided by Qingdao Qingjian New Materials Co., Ltd. (Qingdao, China).

Table 1. Chemical compositions and mineral compositions of HBSAC (\%).

\begin{tabular}{ccccccccc}
\hline $\begin{array}{c}\text { Chemical } \\
\text { Composition }\end{array}$ & $\mathrm{CaO}$ & $\mathrm{SiO}_{2}$ & $\mathrm{Al}_{2} \mathrm{O}_{3}$ & $\mathrm{Fe}_{2} \mathrm{O}_{3}$ & $\mathbf{M g O}$ & $\mathrm{SO}_{3}$ & $\mathrm{TiO}_{2}$ & Loss on Ignition \\
\cline { 2 - 9 } & 45.34 & 12.56 & 20.78 & 2.32 & 3.04 & 13.67 & 0.68 & 0.38 \\
\hline $\begin{array}{c}\text { Mineral } \\
\text { Composition }\end{array}$ & $\mathrm{C}_{4} \mathrm{~A}_{3} \overline{\mathrm{S}}$ & & $\beta-\mathrm{C}_{2} \mathrm{~S}$ & & $\mathrm{C}_{4} \mathrm{~A}_{2.85} \mathrm{Fe}_{1.5} \overline{\mathrm{S}}$ & $\mathrm{C} \overline{\mathrm{S}}$ & $C_{m}$ \\
\cline { 2 - 9 } & 35.77 & & 36.05 & & 8.07 & 14.05 & 1.01 \\
\hline
\end{tabular}

Table 2. Chemical compositions and mineral compositions of OPC (\%).

\begin{tabular}{|c|c|c|c|c|c|c|c|c|}
\hline \multirow{2}{*}{$\begin{array}{l}\text { Chemical } \\
\text { Composition }\end{array}$} & $\mathrm{CaO}$ & $\mathrm{SiO}_{2}$ & $\mathrm{Al}_{2} \mathrm{O}_{3}$ & $\mathrm{Fe}_{2} \mathrm{O}_{3}$ & $\mathrm{MgO}$ & $\mathrm{SO}_{3}$ & $\mathrm{TiO}_{2}$ & Loss on Ignition \\
\hline & 62.73 & 17.8 & 6.38 & 5.83 & 1.94 & 2.98 & 0.52 & 0.38 \\
\hline \multirow{2}{*}{$\begin{array}{c}\text { Mineral } \\
\text { Composition }\end{array}$} & \multicolumn{2}{|c|}{$\mathrm{C}_{3} \mathrm{~S}$} & \multicolumn{2}{|c|}{$\mathrm{C}_{2} \mathrm{~S}$} & \multicolumn{2}{|c|}{$\mathrm{C}_{3} \mathrm{~A}$} & \multicolumn{2}{|r|}{$\mathrm{C}_{4} \mathrm{AF}$} \\
\hline & \multicolumn{2}{|c|}{50.25} & \multicolumn{2}{|c|}{23.31} & \multicolumn{2}{|c|}{7.17} & \multicolumn{2}{|r|}{13.55} \\
\hline
\end{tabular}

Table 3. Performance indexes of natural fine aggregate.

\begin{tabular}{|c|c|c|c|c|c|c|c|}
\hline $\begin{array}{l}\text { Fineness } \\
\text { Module }\end{array}$ & Specifications & $\begin{array}{l}\text { Bulk Density } \\
\left(\mathrm{kg} / \mathrm{m}^{3}\right)\end{array}$ & $\begin{array}{c}\text { Apparent } \\
\text { Density }\left(\mathrm{kg} / \mathrm{m}^{3}\right)\end{array}$ & $\begin{array}{c}\text { Void } \\
\text { Ratio/\% }\end{array}$ & $\begin{array}{l}\text { Micro Powder } \\
\text { Content } / \%\end{array}$ & $\begin{array}{c}\text { Mud } \\
\text { Content/\% }\end{array}$ & $\begin{array}{l}\text { Crushing } \\
\text { Index } / \%\end{array}$ \\
\hline 2.6 & $\begin{array}{c}\text { Medium } \\
\text { sand II class }\end{array}$ & 1450 & 2600 & 40 & 1.1 & 0.7 & 12.5 \\
\hline
\end{tabular}

Table 4. Performance indexes of natural coarse aggregate.

\begin{tabular}{cccccc}
\hline $\begin{array}{c}\text { Water } \\
\text { Absorption/\% }\end{array}$ & $\begin{array}{c}\text { Moisture } \\
\text { Content/\% }\end{array}$ & $\begin{array}{c}\text { Content of Needle-Like } \\
\text { Particles/\% }\end{array}$ & $\begin{array}{c}\text { Crushing } \\
\text { Index/\% }\end{array}$ & $\begin{array}{c}\text { Bulk Density } \\
\mathbf{( k g / \mathbf { m } ^ { 3 } )}\end{array}$ & $\begin{array}{c}\text { Apparent Density } \\
\left(\mathbf{k g} / \mathbf{m}^{\mathbf{3}}\right)\end{array}$ \\
\hline 1.6 & 0.45 & 4.25 & 11.9 & 1458 & 2480 \\
\hline
\end{tabular}

\subsection{Preparation Procedures of $R C A$}

Simple crushing recycled coarse aggregate (JD-RCA), one-time particle-shaping recycled coarse aggregate (KL-RCA), and two-time particle-shaping recycled coarse aggregate (EKL-RCA) were prepared by using a jaw crusher and particle-shaping machine. The appearance and working principle of the particle-shaping equipment are shown in Figure $1 a, b$, 
respectively. The shaping equipment is equipped with a vertical shaft-rotating impeller in the host system. When working, raw materials enter the machine from the upper inlet, a part of the raw materials enter from the middle, accelerate, and are thrown out at high speed due to centrifugal action, while another part of materials enter from the left and right sides and collide with the materials thrown out by the impeller to achieve the purpose of shaping. Therefore, the equipment has the advantages of low wear and energy consumption, small size, simple operation, and green production requirements, and has been put into practical engineering application. The preparation procedures of three types of RCA are shown in Figure 2. The performance index of RCA is shown in Table 5, and its test method refers to Recycled Coarse Aggregate for Concrete (GB/T 25177-2010, China). Table 6 shows the comparison of particle gradation between recycled coarse aggregate and natural coarse aggregate.

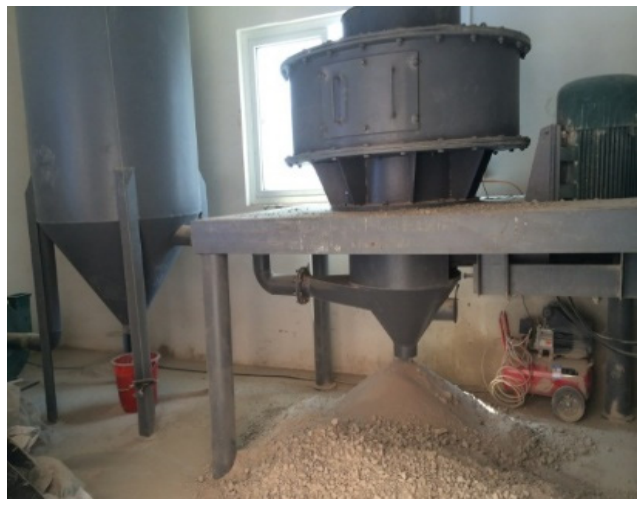

(a)

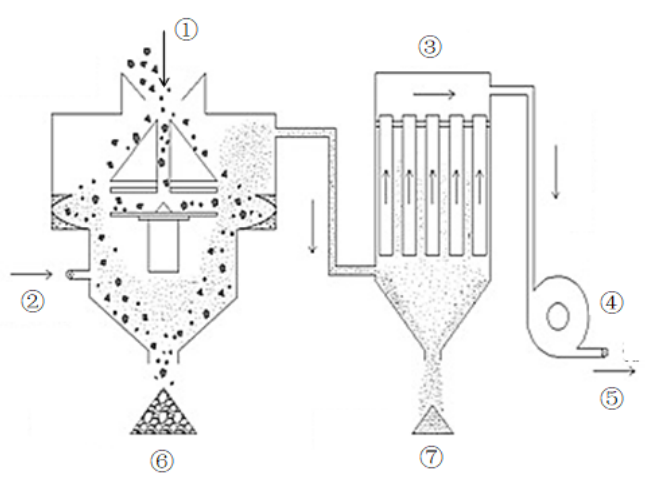

(b)

Figure 1. Particle-shaping strengthening equipment and working principle: (a) equipment appearance and (b) working principle. Note: (1) raw material, (2) air inlet port, (3) dust collector, (4) induced draft fan, (5) air outlet port, (6) granular plastic regenerated aggregate, and (7) recycled powder.

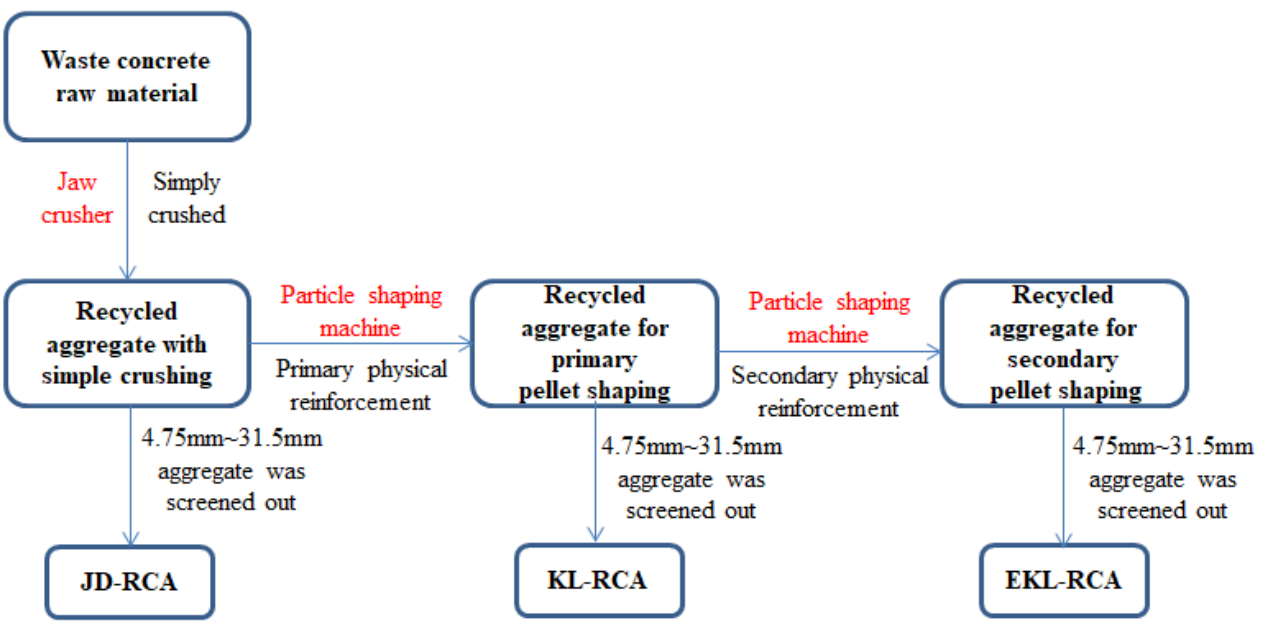

Figure 2. Preparation procedures of three kinds of RCA. 
Table 5. Performance indexes of three kinds of RCA.

\begin{tabular}{cccc}
\hline \multirow{2}{*}{ Projects } & \multicolumn{3}{c}{ Recycled Coarse Aggregates for Trials } \\
\cline { 2 - 4 } & EKL-RCA & KL-RCA & JD-RCA \\
\hline Grain Gradation & Qualified & Qualified & Qualified \\
Powder Content/\% & 0.7 & 0.9 & 2.2 \\
Water Absorption/\% & 1.6 & 2.4 & 3.5 \\
Content of Needle-Like Particles/\% & 1.0 & 4.0 & 7.0 \\
Impurity Content/\% & 0.2 & 0.5 & 0.9 \\
Ruggedness/\% & 3.9 & 4.9 & 9.8 \\
Crushing Index/\% & 9.0 & 14.0 & 17.0 \\
Apparent Density $/\left(\mathrm{kg} / \mathrm{m}^{3}\right)$ & 2475 & 2470 & 2436 \\
Void ratio/\% & 43.0 & 46.0 & 48.0 \\
\hline
\end{tabular}

Table 6. Comparison of aggregate particle gradation.

\begin{tabular}{|c|c|c|c|c|c|c|c|c|c|}
\hline \multirow{3}{*}{ Aggregate Category } & \multirow{3}{*}{$\begin{array}{c}\text { Nominal } \\
\text { Diameter/mm }\end{array}$} & \multicolumn{8}{|c|}{ Accumulated Retained Percentage/\% } \\
\hline & & \multicolumn{8}{|c|}{ The Side Length of the Square Hole Screen/mm } \\
\hline & & 0 & 4.75 & 9.50 & 16.0 & 19.0 & 26.5 & 31.5 & 37.5 \\
\hline Natural coarse aggregate & $5-31.5$ & 99.9 & 97.1 & 63.5 & 28.4 & 15.2 & 1.9 & 0.3 & 0 \\
\hline EKL-RCA & $5-31.5$ & 99.9 & 97.8 & 62.7 & 28.1 & 15.8 & 2.0 & 0.3 & 0 \\
\hline KL-RCA & $5-31.5$ & 99.8 & 98.8 & 74.6 & 35.5 & 21.9 & 2.3 & 0.4 & 0 \\
\hline JD-RCA & $5-31.5$ & 99.7 & 99.2 & 76.6 & 39.6 & 23.3 & 3.2 & 0.5 & 0 \\
\hline
\end{tabular}

As can be seen from Table 5, compared with JD-RCA, the properties of RCA after particle-shaping process, such as micro-powder content, water absorption, needle-like particle content, sundries content, firmness, and the crushing index, are significantly improved, which confirms the effectiveness of preparing high-quality RCA by the particleshaping method.

\subsection{Design of Experiment}

In total, 39 mix proportion ratios were designed in this experiment, and three variables were set: aggregate quality (JD-RCA, KL-RCA, and EKL-RCA), aggregate replacement ratio $(0,25 \%, 50 \%, 75 \%$, and $100 \%)$, and cement cementitious material content $\left(300 \mathrm{~kg} / \mathrm{m}^{3}\right.$, $400 \mathrm{~kg} / \mathrm{m}^{3}$, and $500 \mathrm{~kg} / \mathrm{m}^{3}$ ). The purpose of setting cement cementitious material content as a variable is to prepare recycled concrete with different strength grades. According to "Test Method for Performance of Ordinary Concrete Mixture" (China GB/T50080-2016), the water consumption of concrete is determined by controlling slump in the range of 160 200 mm, which aims to meet the working performance requirements of practical projects. The detailed mixing proportions of concrete are shown in Table 7. 
Table 7. Mixing proportions of concrete $\left(\mathrm{kg} / \mathrm{m}^{3}\right)$.

\begin{tabular}{|c|c|c|c|c|c|c|c|c|}
\hline \multirow{2}{*}{$\begin{array}{c}\text { Item } \\
\text { No. }\end{array}$} & \multirow{2}{*}{$\begin{array}{l}\text { Cement } \\
\text { Content }\end{array}$} & \multicolumn{3}{|c|}{ Recycled Coarse Aggregate } & \multirow{2}{*}{$\begin{array}{c}\text { Natural Coarse } \\
\text { Aggregate }\end{array}$} & \multirow{2}{*}{$\begin{array}{l}\text { Natural Fine } \\
\text { Aggregate }\end{array}$} & \multirow{2}{*}{$\begin{array}{l}\text { Water } \\
\text { Reducer }\end{array}$} & \multirow{2}{*}{$\begin{array}{c}\text { Water } \\
\text { Consumption }\end{array}$} \\
\hline & & Type & $\begin{array}{l}\text { Replacement } \\
\text { Ratio (\%) }\end{array}$ & Content & & & & \\
\hline N1 & 300 & - & 0 & 0 & 1166 & 714 & 3.6 & 150.0 \\
\hline N2 & 300 & EKL-RCA & 25 & 291.5 & 874.5 & 714 & 3.6 & 150.9 \\
\hline N3 & 300 & EKL-RCA & 50 & 583 & 583 & 714 & 3.6 & 153.2 \\
\hline N4 & 300 & EKL-RCA & 75 & 874.5 & 291.5 & 714 & 3.6 & 152.6 \\
\hline N5 & 300 & EKL-RCA & 100 & 1166 & 0 & 714 & 3.6 & 157.9 \\
\hline N6 & 300 & KL-RCA & 25 & 291.5 & 874.5 & 714 & 3.6 & 154.2 \\
\hline N7 & 300 & KL-RCA & 50 & 583 & 583 & 714 & 3.6 & 154.9 \\
\hline N8 & 300 & KL-RCA & 75 & 874.5 & 291.5 & 714 & 3.6 & 155.3 \\
\hline N9 & 300 & KL-RCA & 100 & 1166 & 0 & 714 & 3.6 & 161.2 \\
\hline N10 & 300 & JD-RCA & 25 & 291.5 & 874.5 & 714 & 3.6 & 154.2 \\
\hline N11 & 300 & JD-RCA & 50 & 583 & 583 & 714 & 3.6 & 159.4 \\
\hline N12 & 300 & JD-RCA & 75 & 874.5 & 291.5 & 714 & 3.6 & 164.3 \\
\hline N13 & 300 & JD-RCA & 100 & 1166 & 0 & 714 & 3.6 & 167.2 \\
\hline N14 & 400 & - & 0 & 0 & 1136 & 696 & 4.8 & 152.2 \\
\hline N15 & 400 & EKL-RCA & 25 & 284 & 852 & 696 & 4.8 & 153.3 \\
\hline N16 & 400 & EKL-RCA & 50 & 568 & 568 & 696 & 4.8 & 152.6 \\
\hline N17 & 400 & EKL-RCA & 75 & 852 & 284 & 696 & 4.8 & 160.3 \\
\hline N18 & 400 & EKL-RCA & 100 & 1136 & 0 & 696 & 4.8 & 159.6 \\
\hline N19 & 400 & KL-RCA & 25 & 284 & 852 & 696 & 4.8 & 153.3 \\
\hline N20 & 400 & KL-RCA & 50 & 568 & 568 & 696 & 4.8 & 158.6 \\
\hline N21 & 400 & KL-RCA & 75 & 852 & 284 & 696 & 4.8 & 159.9 \\
\hline N22 & 400 & KL-RCA & 100 & 1136 & 0 & 696 & 4.8 & 163.8 \\
\hline N23 & 400 & JD-RCA & 25 & 284 & 852 & 696 & 4.8 & 157.8 \\
\hline N24 & 400 & JD-RCA & 50 & 568 & 568 & 696 & 4.8 & 161.2 \\
\hline N25 & 400 & JD-RCA & 75 & 852 & 284 & 696 & 4.8 & 165.2 \\
\hline N26 & 400 & JD-RCA & 100 & 1136 & 0 & 696 & 4.8 & 169.6 \\
\hline N27 & 500 & - & 0 & 0 & 1106 & 678 & 6.0 & 154.3 \\
\hline N28 & 500 & EKL-RCA & 25 & 276.5 & 829.5 & 678 & 6.0 & 155.6 \\
\hline N29 & 500 & EKL-RCA & 50 & 553 & 553 & 678 & 6.0 & 155.5 \\
\hline N30 & 500 & EKL-RCA & 75 & 829.5 & 276.5 & 678 & 6.0 & 156.9 \\
\hline N31 & 500 & EKL-RCA & 100 & 1106 & 0 & 678 & 6.0 & 161.3 \\
\hline N32 & 500 & KL-RCA & 25 & 276.5 & 829.5 & 678 & 6.0 & 156.3 \\
\hline N33 & 500 & KL-RCA & 50 & 553 & 553 & 678 & 6.0 & 163.5 \\
\hline N34 & 500 & KL-RCA & 75 & 829.5 & 276.5 & 678 & 6.0 & 162.3 \\
\hline N35 & 500 & KL-RCA & 100 & 1106 & 0 & 678 & 6.0 & 165.8 \\
\hline N36 & 500 & JD-RCA & 25 & 276.5 & 829.5 & 678 & 6.0 & 159.9 \\
\hline N37 & 500 & JD-RCA & 50 & 553 & 553 & 678 & 6.0 & 163.6 \\
\hline N38 & 500 & JD-RCA & 75 & 829.5 & 276.5 & 678 & 6.0 & 167.1 \\
\hline N39 & 500 & JD-RCA & 100 & 1106 & 0 & 678 & 6.0 & 171.5 \\
\hline
\end{tabular}

\section{Experimental Methods}

\subsection{Compressive Strength}

According to the Test Method for Physical and Mechanical Properties of Concrete (GB/T 50081-2019, China), the compressive strength of concrete is tested for 1 day, 3 day, 7 day, and 28 day, respectively, by using $100 \mathrm{~mm} \times 100 \mathrm{~mm} \times 100 \mathrm{~mm}$ cube test specimens and carrying out standard curing.

\subsection{Shrinkage Test}

The method for drying shrinkage performance of green recycled aggregate concrete (RAC) is carried out according to the Standard for Test Methods for Long-Term Performance and Durability of Ordinary Concrete (GB/T 50082-2009, China), The cuboid specimens of $100 \mathrm{~mm} \times 100 \mathrm{~mm} \times 515 \mathrm{~mm}$ were put into a constant temperature and humidity chamber with temperature of $20 \pm 2{ }^{\circ} \mathrm{C}$ and relative humidity of $60 \% \pm 5 \%$ immediately after curing 
for $1 \mathrm{~d}$. The initial length was recorded, and the shrinkage changes were measured at intervals of $1 \mathrm{~d}, 3 \mathrm{~d}, 7 \mathrm{~d}, 28 \mathrm{~d}, 45 \mathrm{~d}, 60 \mathrm{~d}, 90 \mathrm{~d}, 120 \mathrm{~d}, 150 \mathrm{~d}$, and $180 \mathrm{~d}$, respectively.

High belite sulphoaluminate cement has micro-expansion and crack resistance, which can make the shrinkage change of green RAC smaller. Therefore, a new fixed vertical shrinkage dilatometer was used in the test. The appearance and working principle of the equipment are shown in Figure 3a,b. The advantage of this equipment is that the four-claw anchoring iron plate is embedded in the bottom of the test block to ensure the integration with the equipment and prevent the experimental error caused by the loosening of the two. In addition, the internal twist screw is embedded at the top of the test specimens, which can install a fixed small platform to contact with the dial indicator point and surface, so as to avoid the shift of the position of the embedded probe in the concrete molding process or the loose drop of the probe in the concrete formwork removal process, and thus indirectly improve the data accuracy.

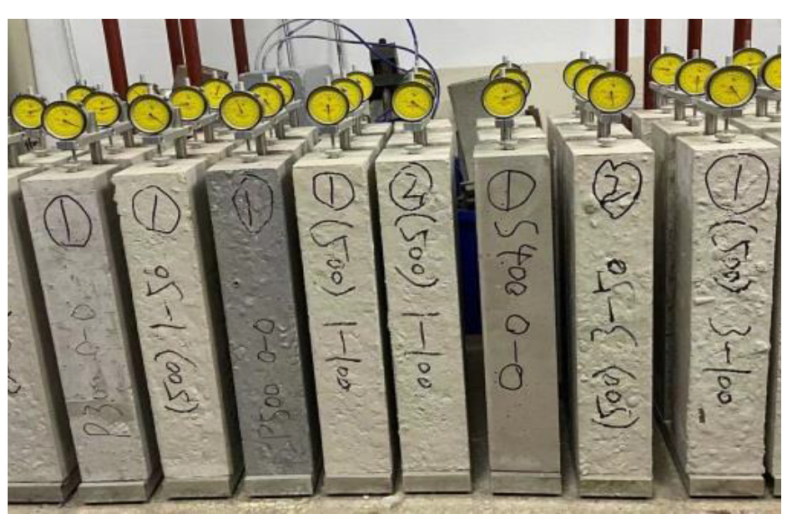

(a)

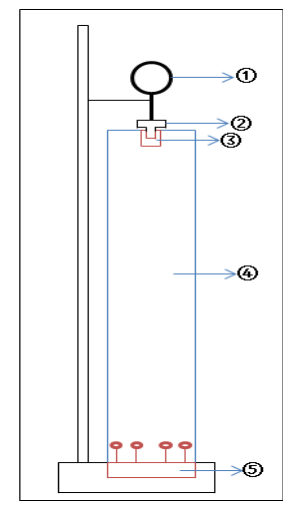

(b)

Figure 3. Concrete shrinkage dilatometer: (1) dilatometer, (2) fixed small platform, (3) internal twist screw, (4) test block, and (5) fixed small platform. (a) Equipment appearance and (b) working principle.

The shrinkage rate of green RAC is calculated according to the following formula:

$$
\varepsilon_{s t}=\frac{L_{0}-L_{t}}{L_{b}}
$$

where $\varepsilon_{s t}$ refers to the shrinkage rate of concrete specimen $t(\mathrm{~d}), L_{0}$ refers to the initial length reading $(\mathrm{mm}), L_{t}$ refers to the measurement reading $(\mathrm{mm})$ at test piece $t(\mathrm{~d})$, and $L_{b}$ refers to the gauge distance $(\mathrm{mm})$ of the specimen.

\subsection{Microstructural Characterization}

A scanning electron microscope (FEG-SEM, JSM 7500f, Jeol, Tokyo, Japan) was used to observe the microstructure of high belite sulphoaluminate cement paste under different multiples, including void and crack structure, and compared with ordinary Portland cement paste.

\section{Results and Discussion}

4.1. Effect of RCA Quality and the Replacement Ratio on Mechanical Properties of HBRAC

Figure 4 shows the effect of RCA quality and the replacement ratio on concrete compressive strength under different cementitious material content. 


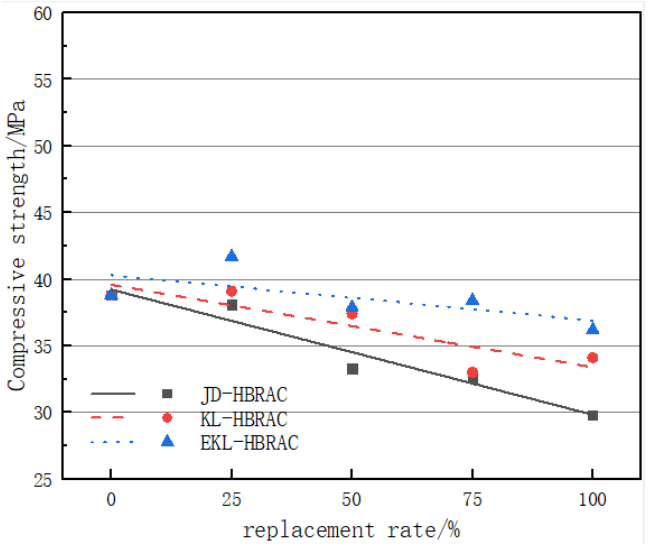

(a)

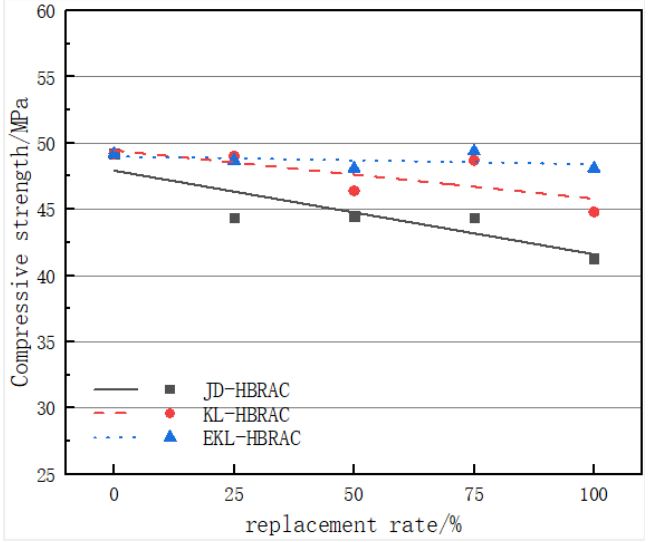

(b)

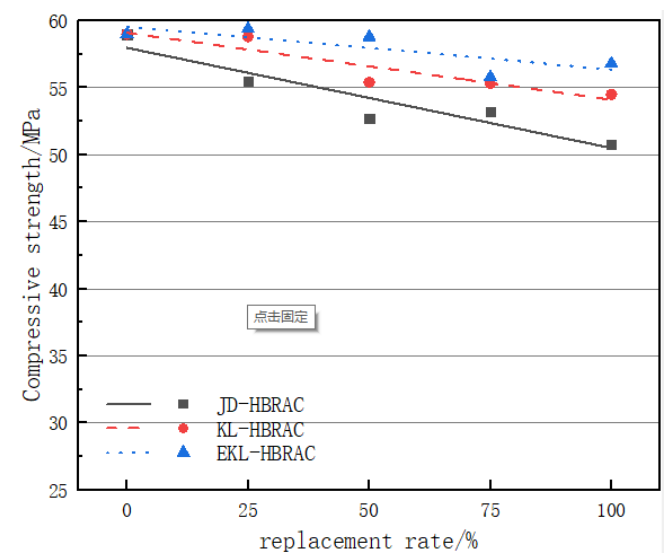

(c)

Figure 4. Effect of RCA quality and the replacement ratio on compressive strength of HBRAC: (a) cementitious material content $300 \mathrm{~kg} / \mathrm{m}^{3}$, (b) cementitious material content $400 \mathrm{~kg} / \mathrm{m}^{3}$, and (c) cementitious material content $500 \mathrm{~kg} / \mathrm{m}^{3}$.

It can be seen from Figure 4 that there are obvious differences in the effect of RCAs with different qualities on 28-day compressive strength of HBRAC, and the difference is most obvious when the replacement ratio of RCAs is $100 \%$. Specifically, compared with the strength of high belite sulphoaluminate cement-based recycled concrete with simple crushed recycled coarse aggregate (JD-HBRAC), the average strength growth rate of high belite sulphoaluminate cement-based recycled concrete with one-time particle-shaping recycled coarse aggregate (KL-HBRAC) is $11.4 \%$, and that of high belite sulphoaluminate cement-based recycled concrete with two-time particle-shaping recycled coarse aggregate (EKL-HBRAC) is $18.5 \%$. The main reasons are likely to be that more internal micro-cracks of JD-RCA in the support of concrete skeleton effect are much worse, and the surface of the aggregate contains large water absorption of the old mortar and other impurities, resulting in increased water consumption of concrete and decreased compressive strength. KL-RCA is a kind of aggregate with better performance, which is made of JD-RCA by grinding all kinds of impurities and prominent edges and corners on the surface of aggregate with the particle-shaping machine, and the grain surface changes from rough to smooth, and the grain shape changes from irregular to spherical. The improvement of aggregate performance not only reduces the weak layer of new and old interface in concrete, but also greatly reduces the demand of concrete for water consumption and improves the overall compressive strength of concrete. The performance of EKL-RCA is more stable than that of KL-RCA. The most important point is to polish and remove the aggregate containing mortar and irregular water chestnut, which still exists in the first particle shaping, so that the 
aggregate tends to be more spherical and effectively reduces the content of flaky aggregate. Therefore, the compressive strength of JD-HBRAC is the worst, the compressive strength of EKL-HBRAC is the best, and the compressive strength of KL-HBRAC is in between.

It can also be seen from Figure 4 that there is a high linear correlation between the $28 \mathrm{~d}$ compressive strength of the HBRAC and the RAC replacement ratio; that is, the compressive strength of HBRAC decreases with the increase of RAC replacement ratio, but the strength decrease range of concrete is different with the increase of the RAC replacement ratio, which has a great relationship with the quality of RCA. Specifically, compared with NA-HBNC, the compressive strength of JD-HBRAC, KL-HBRAC, and EKL-HBRAC varies with the replacement ratios of $25 \%, 50 \%, 75 \%$, and $100 \%$, and the average strength reduction rates respectively decrease by the following percentages: $5.1 \%$, $10.0 \%, 12.8 \%$, and $17.9 \% ; 0.3 \%, 5.0 \%, 6.5 \%$, and $8.6 \%$; and $-2.3 \%, 1.8 \%, 3.4 \%$, and $2.9 \%$. According to the data, the average strength reduction rate of JD-HBRAC can reach about $18.0 \%$, and the compressive strength decreases obviously after the replacement ratio of JD-RCA is higher than $25 \%$. Therefore, it can be ensured that the compressive strength of HBRAC and JD-RCA is only suitable for replacing natural aggregate with low content, and the best replacement ratio is $25 \%$. The average strength reduction rate of RCA after particle-shaping treatment is obviously lower and even lower than 3.5\% after two-time particle shaping. It is worth noting that when the replacement ratio of RCA by two-time particle shaping is $25 \%$, the compressive strength of HBRAC prepared by replacing the natural aggregate is even higher than that of natural aggregate concrete, which is because the performance of aggregate after two-time particle shaping is more stable, the shape is closer to spherical, the surface-hardened mortar is removed more fully, the aggregate gradation is more reasonable, and the combination effect with cement paste is better, so the concrete prepared by HBRAC can achieve a higher strength.

\subsection{Effect of Cementitious Material Content on Mechanical Properties of HBRAC}

Figure 5 shows the effect of cementitious material content on the compressive strength of RAC.

It can be seen from Figure 5 that the cementitious material content keeps a high consistency with the strength growth law, and the cementitious material content has a great influence on the mechanical properties of HBRAC, and the strength growth rate can reach about $35 \%$. When the replacement ratio of RCA is $100 \%$, the cementitious material content is increased from $300 \mathrm{~kg} / \mathrm{m}^{3}$ to $400 \mathrm{~kg} / \mathrm{m}^{3}$, and the compressive strength of JP-HBRAC, KLHBRAC, and EKL-HBRAC is increased by $11.5 \mathrm{MPa}, 12.7 \mathrm{MPa}$ and $11.9 \mathrm{MPa}$, respectively, and the strength growth rates are $38.6 \%, 35.4 \%$, and $32.9 \%$, respectively. The increase of compressive strength is because the more cementitious materials are used, more hydration products are obtained by reacting with water, and there is a better combination effect with aggregate, so that the structure of HBRAC is denser; thus, it significantly improves the mechanical properties of HBRAC. In addition, the strength growth rate of HBRAC with different quality aggregates is different. The strength growth rate of JP-HBRAC is the largest, KL-HBRAC is the second, and EKL-HBRAC is the smallest. This is because, on the one hand, high belite sulphoaluminate cement has the effect of rapid setting and hardening; it can accelerate the hydration process of cement, and form a large amount of ettringite in the early stage. The accumulation of ettringite itself and the volume increase in the reaction process, that is, the micro-expansion performance, not only fill the internal voids of RCA, but also improve the interface weak layer to a certain extent in a short time. On the other hand, compared with ordinary Portland cement, the gel types in this cement are more aluminum glue, which can enhance the bonding strength to the interface zone of RCA during the reaction process. Therefore, with the increase of the cementitious material content, the more ettringite and aluminum glue produced, the better the effect of improving the void and interface structure of low-quality RCA with more internal voids, and the higher the strength growth rate. 


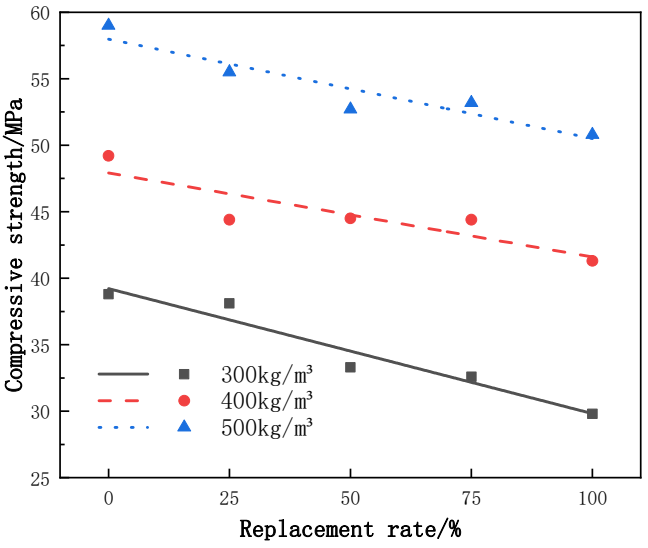

(a)

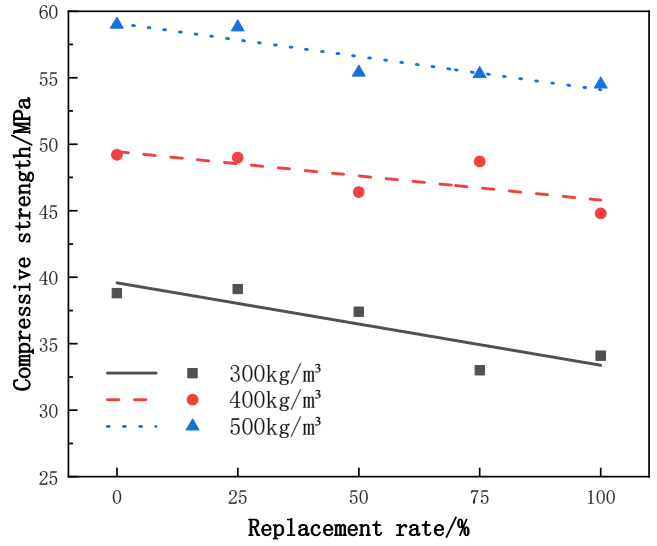

(b)

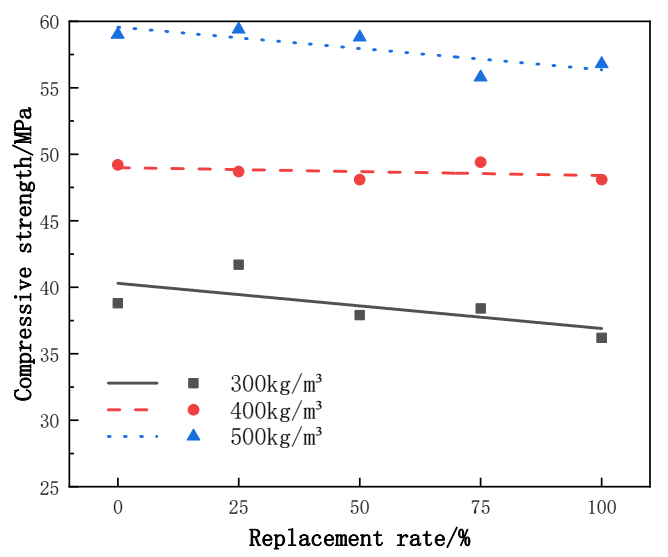

(c)

Figure 5. Effect of cementitious material content on compressive strength of RAC: (a) JD-HBRAC, (b) KL-HBRAC, and (c) EKL-HBRAC.

\subsection{Comparison of Mechanical Properties between HBRAC and OPRAC}

Figure 6 shows the comparison of compressive strength of high belite sulphoaluminate cement-based recycled aggregate concrete (HBRAC) and ordinary Portland cement-based recycled aggregate concrete (OPRAC) at different ages with different cementitious material content when the replacement ratio of three kinds of RCA is $100 \%$.

It can be seen from Figure $6 \mathrm{a}$ that the compressive strength of JD-HBRAC, KL-HBRAC, and EKL-HBRAC in $1 \mathrm{~d}$ reaches $73.8 \%, 73.9 \%$, and $79.8 \%$ of the $28 \mathrm{~d}$ compressive strength, respectively, the $28 \mathrm{~d}$ compressive strength values are $29.8 \mathrm{MPa}, 34.1 \mathrm{MPa}$, and $36.2 \mathrm{MPa}$, respectively, and the $150 \mathrm{~d}$ compressive strength can reach $38.9 \mathrm{MPa}, 43.3 \mathrm{MPa}$, and 45.4 MPa, respectively. The compressive strength of JD-OPRAC, KL-OPRAC, and EKLOPRAC at $1 \mathrm{~d}$ is $30.6 \%, 29.7 \%$, and $33.1 \%$ of the $28 \mathrm{~d}$ compressive strength, it is $27.8 \mathrm{MPa}$, 33.7 MPa, and $34.4 \mathrm{MPa}$ at $28 \mathrm{~d}$, and it is $35.6 \mathrm{MPa}, 40.2 \mathrm{MPa}$, and $43.9 \mathrm{MPa}$ at $150 \mathrm{~d}$, respectively. Comparing the data of the two groups, it can be seen that HBRAC has fast hardening performance in the early stage, and the compressive strength of $1 \mathrm{~d}$ can reach more than $70 \%$ in $28 \mathrm{~d}$, which is much higher than OPRAC. At $28 \mathrm{~d}$ and $150 \mathrm{~d}$ of age, HBRAC still maintained high intensity and was slightly higher than OPRAC. This is due to the rapid reaction between sulphoaluminate and gypsum in the early stage, which produces a large amount of aluminum gum and gel, and quickly combines with RCA to form a whole to achieve short-term improvement of concrete strength. In the later stage, the interlaced bonding of ettringite with gel and aluminum glue not only enhances the encapsulation force of aggregate and improves the compactness of concrete, but also changes its internal structure and makes it more compact and firmer as a whole. Therefore, 
HBRAC not only has early strength and quick hardening, but also can maintain a higher strength value in the middle and late stages.

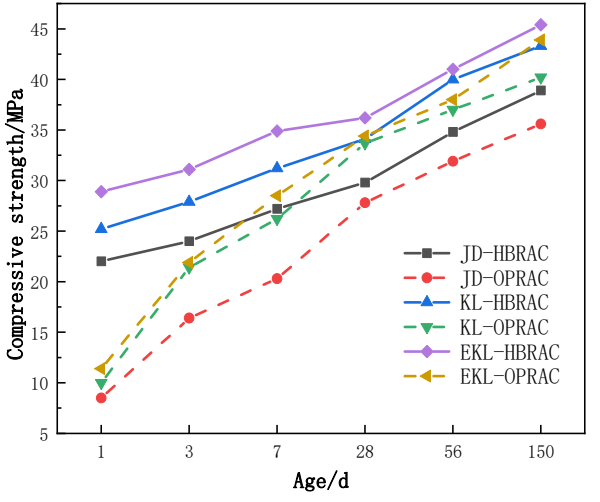

(a)

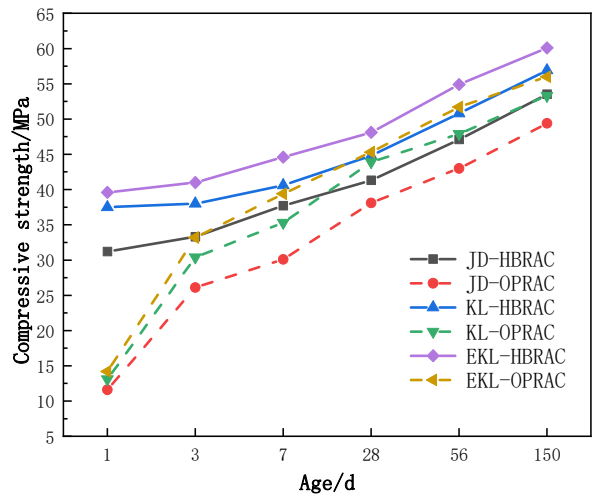

(b)

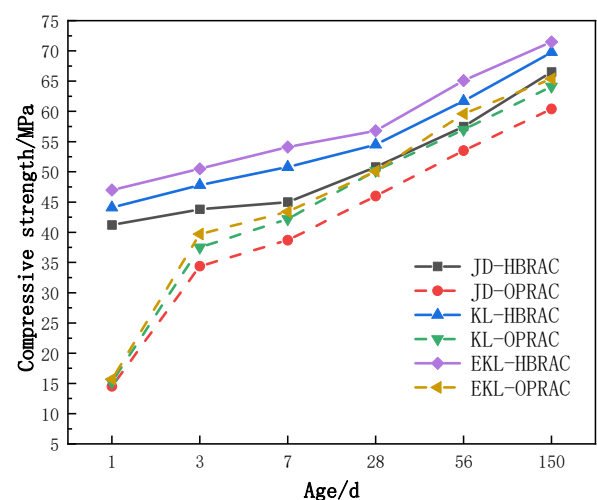

(c)

Figure 6. Comparison of compressive strength of HBRAC and OPRAC at different ages: (a) cementitious material content $300 \mathrm{~kg} / \mathrm{m}^{3}$, (b) cementitious material content $400 \mathrm{~kg} / \mathrm{m}^{3}$, and (c) cementitious material content $500 \mathrm{~kg} / \mathrm{m}^{3}$.

It can be seen from Figure 6 that the 150-day compressive strength of HBRAC is 2.6 MPa, 3.9 MPa, and 6.0 MPa higher than that of OPRAC on average when the cementitious material content varies from $300 \mathrm{~kg} / \mathrm{m}^{3}, 400 \mathrm{~kg} / \mathrm{m}^{3}$, and $500 \mathrm{~kg} / \mathrm{m}^{3}$, respectively. It can be seen that with the increase of cementitious materials, the greater the difference of compressive strength between the two kinds of cement concrete and the greater the advantage of HBRAC, which shows that the more cement particles in HBRAC, the better the combination of gel and aggregate formed after hydration reaction, and the denser the structure, the easier it is to form a gap with OPRAC in compressive strength.

\subsection{Effect of RCA Quality and the Replacement Ratio on Shrinkage Performance of HBRAC}

Figure 7 shows the effect of RCA quality and the replacement ratio on drying shrinkage of RAC under different cementitious material contents. In the figure, NA represents natural aggregate concrete; JD-50\%, KL-50\%, and EKL-50\% respectively represent simple crushed recycled concrete, one-time particle-shaped recycled concrete, and two-time particle-shaped recycled concrete with an aggregate replacement ratio of $50 \%$. JD- $100 \%, \mathrm{KL}-100 \%$, and EKL-100\% respectively represent simple crushed recycled concrete, one-time particleshaped recycled concrete, and two-time particle-shaped recycled concrete with an aggregate replacement ratio of $100 \%$. 


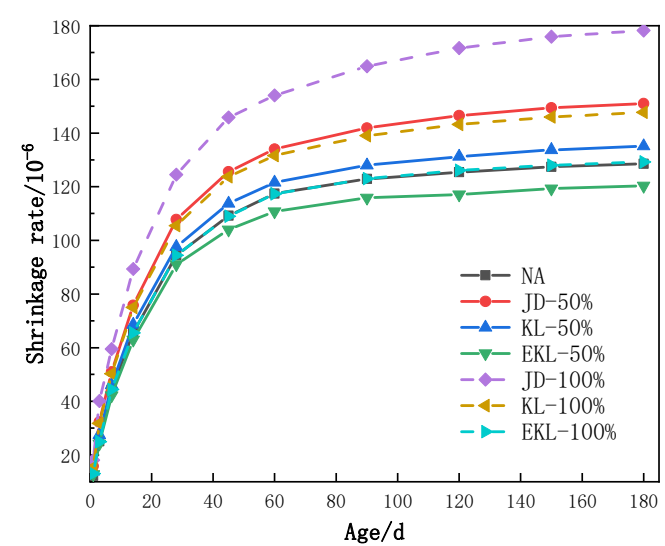

(a)

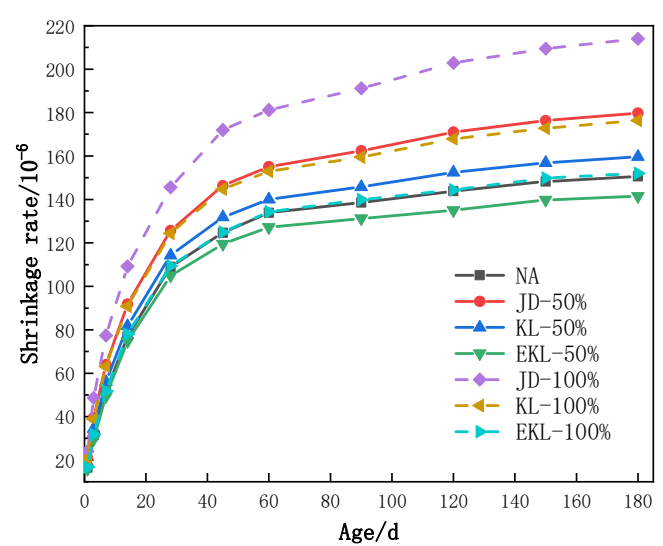

(b)

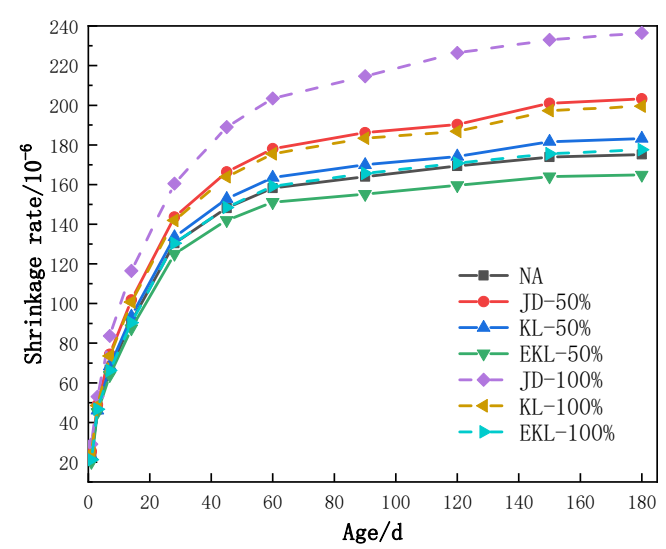

(c)

Figure 7. Effect of RCA quality and the replacement ratio on drying shrinkage of HBRAC: (a) cementitious material content $300 \mathrm{~kg} / \mathrm{m}^{3}$, (b) cementitious material content $400 \mathrm{~kg} / \mathrm{m}^{3}$, and (c) cementitious material content $500 \mathrm{~kg} / \mathrm{m}^{3}$.

As can be seen from Figure 7, with the improvement of RCA quality, the shrinkage rate of HBRAC decreases. The shrinkage of EKL-HBRAC is the smallest, KL-HBRAC is the second, and JD-HBRAC is the largest and obviously higher than KL-HBRAC and EKL-HBRAC. This is due to the fact that there are still a large number of slurries with high water absorption on the surface of JD-RCA, and the elastic modulus of the aggregate that can inhibit shrinkage is low. However, one-time particle shaping can remove the old interface of aggregate old mortar, improve the overall elastic modulus, and greatly narrow the performance gap with natural aggregate. Two-time particle shaping can consolidate or even improve the aggregate performance, and the shrinkage performance can even be compared with that of natural aggregate, which further shows that the particle-shaping method has significant advantages in improving the shrinkage performance of RAC.

From Figure 7, it also can be seen that the replacement ratio of RCA has no less influence on the drying shrinkage performance of green concrete than the quality of RCA. The contraction values of JD-HBRAC and KL-HBRAC increased with the increase of the replacement ratio. This is because the higher the replacement ratio of RCA with a high water absorption rate, the more water the concrete needs to meet the slump of the project; that is, the water-binder ratio increases, which leads to more and more capillary channels formed by continuous water evaporation in concrete, and the negative pressure value in the holes becomes larger, which increases the drying shrinkage of concrete. For EKL-HBRAC, the shrinkage of EKL-HBRAC is smaller than that of natural concrete when the replacement ratio is $50 \%$, and there is little difference between EKL-HBRAC and natural concrete when the replacement ratio is $100 \%$. This is because the secondary shaping of EKL-RCA can 
not only greatly reduce the content of the needle-flake aggregate, but also can peel off the surface mortar with high water absorption and make the particle shape of aggregate tend to be spherical, and the aggregate gradation is better, which greatly improves the shrinkage performance of RAC prepared by EKL-RCA.

\subsection{Effect of Cementitious Material Content on the Shrinkage Performance of HBRAC}

Figure 8 shows the effect of cementitious material content on the drying shrinkage performance of HBRAC under different RCA quality. In the figure, $50 \%-300 \mathrm{~kg} / \mathrm{m}^{3}$, $50 \%-400 \mathrm{~kg} / \mathrm{m}^{3}$, and $50 \%-500 \mathrm{~kg} / \mathrm{m}^{3}$ refer to recycled concrete with cementitious materials of $300 \mathrm{~kg} / \mathrm{m}^{3}, 400 \mathrm{~kg} / \mathrm{m}^{3}$, and $500 \mathrm{~kg} / \mathrm{m}^{3}$, respectively, on the premise that the aggregate replacement ratio is $50 \%$. The values of $100 \%-300 \mathrm{~kg} / \mathrm{m}^{3}, 100 \%-400 \mathrm{~kg} / \mathrm{m}^{3}$, and $100 \%-500 \mathrm{~kg} / \mathrm{m}^{3}$ refer to recycled concrete with cementitious materials of $300 \mathrm{~kg} / \mathrm{m}^{3}$, $400 \mathrm{~kg} / \mathrm{m}^{3}$, and $500 \mathrm{~kg} / \mathrm{m}^{3}$, respectively, on the premise that the aggregate replacement ratio is $100 \%$.

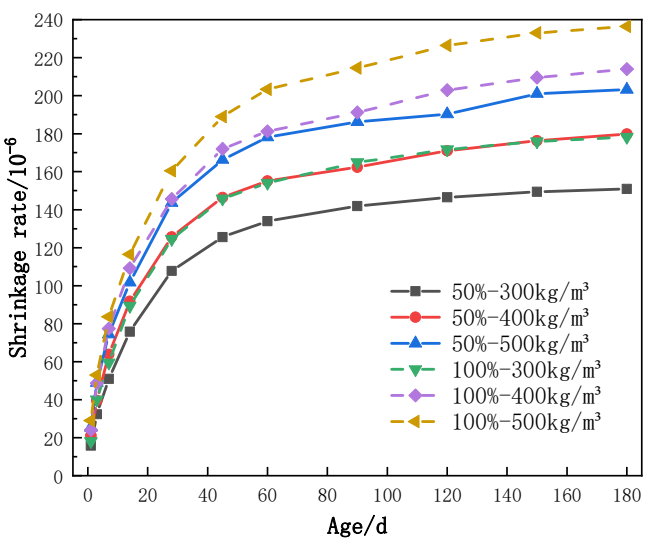

(a)

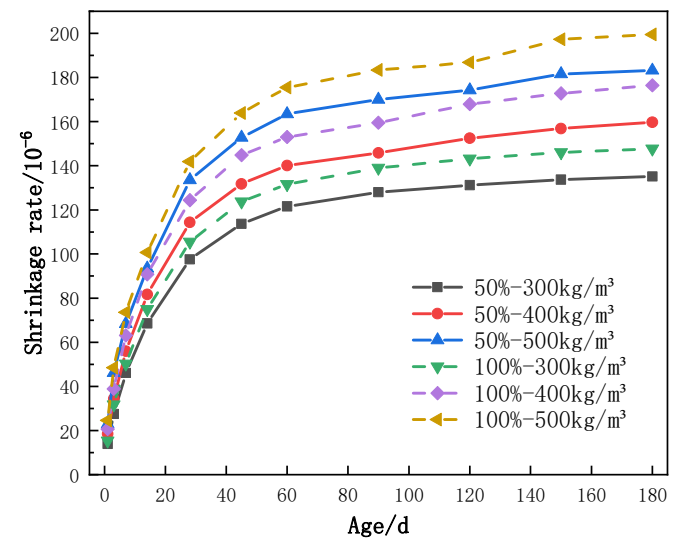

(b)

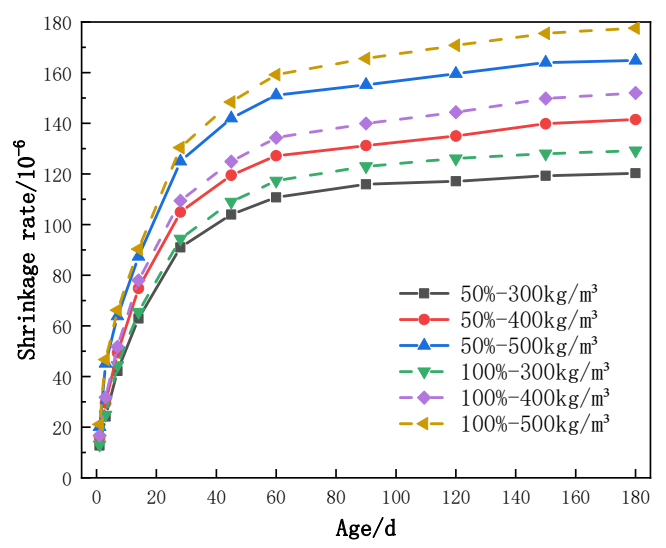

(c)

Figure 8. Effect of cementitious material content on the drying shrinkage performance of RAC: (a) 'JD-HBRAC, (b) KL-HBRAC, and (c) EKL-HBRAC.

It can be seen from Figure 8 that the cementitious material content has obvious influence on the shrinkage performance of green concrete. With the increase of cementitious material content, the shrinkage rate increases. Specifically, compared with $300 \mathrm{~kg} / \mathrm{m}^{3}$ of cementitious material, the 180-day shrinkage of HBRAC with $400 \mathrm{~kg} / \mathrm{m}^{3}$ of cementitious material increased by about $17.6 \%-20.1 \%$, and that of HBRAC with $500 \mathrm{~kg} / \mathrm{m}^{3}$ of cementitious material increased by about $32.7 \%-37.6 \%$. The analysis of the above data shows that it is caused by the joint action of the two aspects. On the one hand, regarding the cement cementitious material as a flexible material of cementitious bonding, the greater its content, 
the stronger its flexible effect and the greater its absolute shrinkage. On the other hand, regarding aggregate as a rigid material, the less its content, the weaker its rigid shrinkage inhibition ability.

\subsection{Comparison of the Shrinkage Performance between HBRAC and OPRAC}

Figure 9 shows the comparison of the drying shrinkage performance of high belite sulphoaluminate cement-based recycled aggregate concrete (HBRAC) and ordinary Portland cement-based recycled aggregate concrete (OPRAC) at different ages with different cementitious material content when the replacement ratio of the three kinds of RCA is $100 \%$.

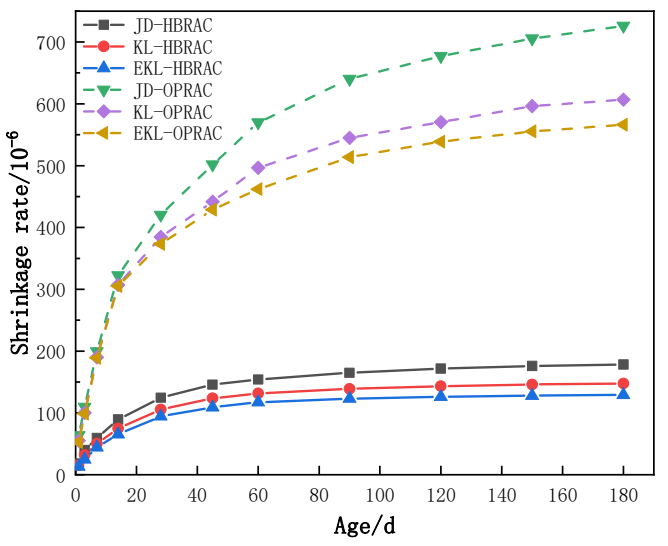

(a)

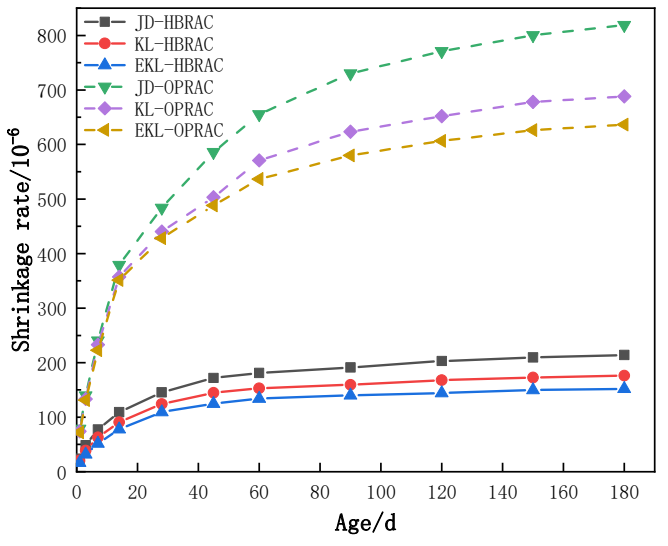

(b)

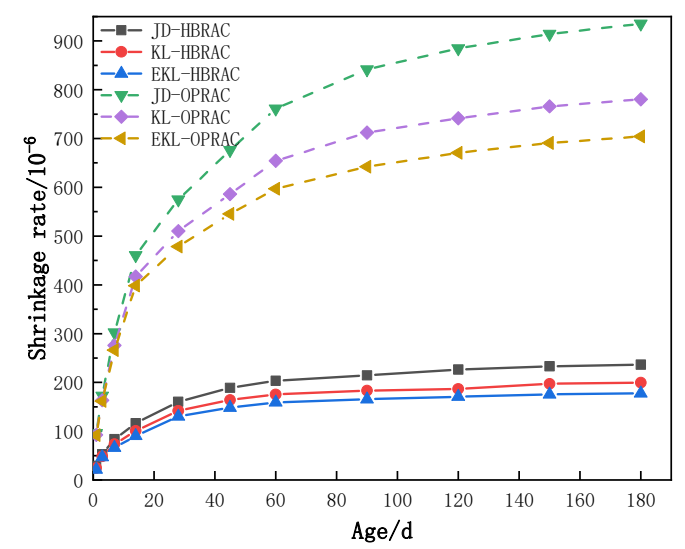

(c)

Figure 9. Comparison of drying shrinkage performance of HBRAC and OPRAC at different ages: (a) cementitious material content $300 \mathrm{~kg} / \mathrm{m}^{3}$, (b) cementitious material content $400 \mathrm{~kg} / \mathrm{m}^{3}$, (c) and cementitious material content $500 \mathrm{~kg} / \mathrm{m}^{3}$.

As can be seen from Figure 9a, the 180-day shrinkage values of JD-OPRAC, KLOPRAC, and EKL-OPRAC are $566.2 \times 10^{-6}, 606.8 \times 10^{-6}$, and $726.1 \times 10^{-6}$, respectively, while the $180 \mathrm{~d}$ shrinkage values of JD-HBRAC, KL-HBRAC, and EKL-HBRAC are $129.2 \times 10^{-6}, 147.7 \times 10^{-6}$, and $178.2 \times 10^{-6}$, respectively. Compared with OPRAC, the drying shrinkage is reduced by $77.2 \%, 75.7 \%$, and $75.5 \%$, respectively. In addition, the shrinkage curve of HBRAC at $45 \mathrm{~d}$ is basically flat, and its shrinkage rate accounted for $80.0 \%-84.4 \%$ of the $180 \mathrm{~d}$ shrinkage rate, while the shrinkage curve of OPRAC tends to be flat at $60 \mathrm{~d}$, and its shrinkage rate accounted for $80.0 \%-84.8 \%$ of the $180 \mathrm{~d}$ shrinkage rate. It can be seen that the drying shrinkage of HBRAC not only increases slowly, but also is far lower than that of OPRAC, which has excellent anti-drying shrinkage ability and ensures that the shrinkage can be reduced to more than $75 \%$. This is due to the shrinkage compensation of ettringite produced by hydration of anhydrous calcium sulfate in high 
belite sulphoaluminate cement, which makes the cement slurry dense, reduces the number of micro-cracks, and improves the overall volume stability of concrete. At the same time, it not only shows that the influence of cement varieties on the shrinkage performance of RAC is far greater than the cementitious material content, aggregate quality, and replacement ratio, but also proves the effectiveness of high belite sulphoaluminate cement in reducing the shrinkage of RAC.

\subsection{Microstructural Analysis}

Drying shrinkage is the shrinkage deformation caused by water loss in the inner void of concrete, which results in the generation of dry shrinkage cracks. In order to study the effect of high belite sulphoaluminate cement and ordinary Portland cement on the dry shrinkage of concrete, the micro-morphology of hydration products of the two kinds of cement at an early stage and $28 \mathrm{~d}$ of age were analyzed by SEM under 1000 times, as shown in Figure 10.

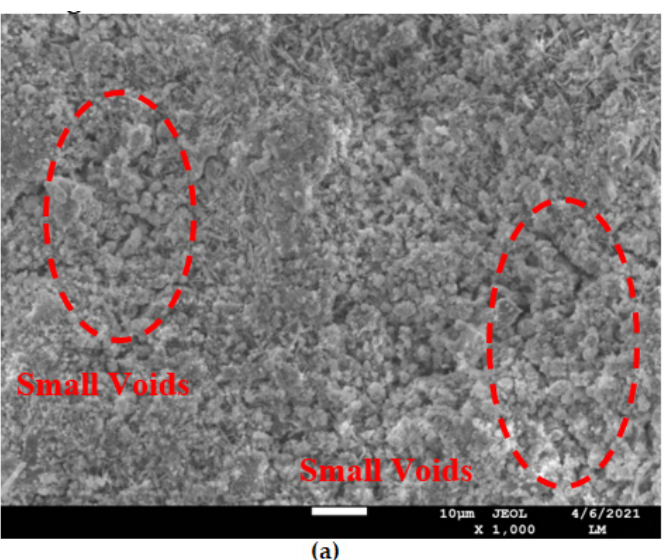

(a)

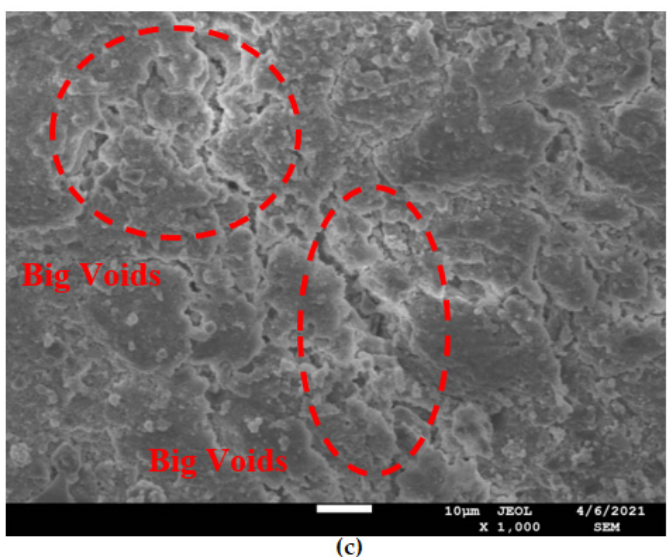

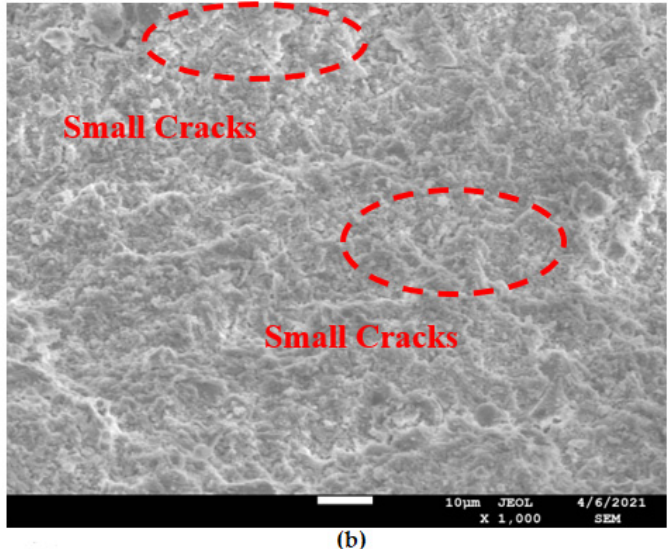

(b)

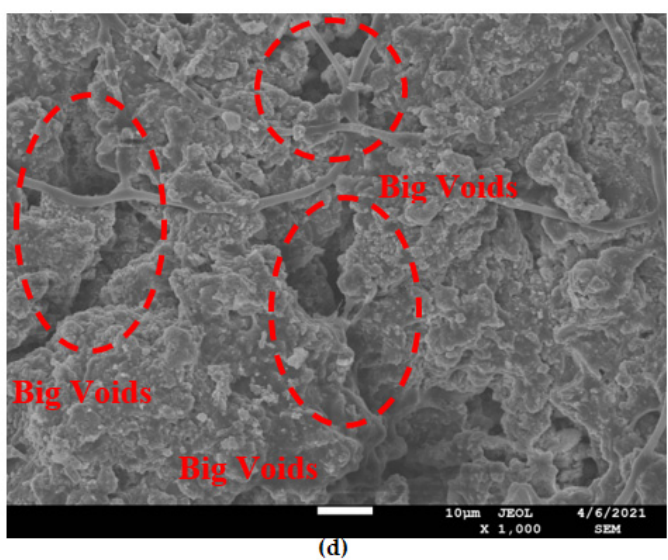

Figure 10. SEM images of HBSAC cement paste and OPC cement paste at 1 day and 28 days of age: (a) HBSAC $1 \mathrm{~d}$, (b) HBSAC 28 d, (c) OPC 3 d, and (d) OPC 28 d.

From Figure 10a,b, it can be seen that only small voids exist in HBSAC cement paste structure after hydration for $1 \mathrm{~d}$, which is due to the fact that fine needle-like or coarse needle-like ettringite is wrapped by a large number of flocculent gels, so that the voids can be filled, and the paste structure is denser and only fine cracks appear after hydration for $28 \mathrm{~d}$. As can be seen from Figure 10c,d, there are a lot of deep and large voids in the structure of OPC cement paste after hydration for $3 \mathrm{~d}$, because the early hydration reaction of OPC cement is slow, and the hydration products are mainly lamellar calcium hydroxide and flocculent C-S-H gel, and the voids in the structure of OPC cement paste have not been well filled. After hydration for $28 \mathrm{~d}$, there are still obvious macrovoids in the structure of OPC cement paste. Therefore, HBSAC cement has a fast hydration reaction, dense 
paste structure, and few cracks, which can resist drying shrinkage caused by water loss, while OPC cement has slow strength growth and more voids in paste, which increases the number of water loss channels and capillary voids, resulting in the poor drying shrinkage performance of concrete. This proves the effectiveness of preparing recycled concrete with high belite sulphoaluminate cement to improve its shrinkage performance from microscopic aspects.

\section{Conclusions}

In this study, high-quality recycled coarse aggregate was prepared by recycled aggregate preparation technology and used in recycled aggregate concrete together with high belite sulphoaluminate cement with excellent performance. The effects of the recycled coarse aggregate quality, the replacement ratio of recycled coarse aggregate, and the amount of cement cementitious material on the mechanical properties and shrinkage properties of recycled aggregate concrete were analyzed and compared with those of ordinary Portland cement-based recycled aggregate concrete, and the main conclusions are as follows:

(1) Compared with the simple crushing strengthening process of recycled aggregate, the particle-shaping and strengthening technology significantly improves the performance indexes of recycled coarse aggregate, and the performance of two-time particle-shaping aggregate is better than that of one-time particle-shaping aggregate, which further proves the effectiveness of preparing high-quality recycled coarse aggregate by particle-shaping method.

(2) Recycled concrete prepared from recycled coarse aggregate with particle shaping can keep high compressive strength. Compared with natural aggregate concrete, the compressive strength of JD-HBRAC can be reduced by about $18.0 \%$, while the compressive strength of KL-HBRAC and EKL-HBRAC can be reduced significantly; even the compressive strength of EKL-HBRAC can be reduced to less than $3.5 \%$. In addition, the cementitious material content has a great influence on the compressive strength of recycled concrete. With the increase of the cementitious material content, the strength growth rate can reach about $35 \%$.

(3) The drying shrinkage of recycled concrete prepared by particle-shaped recycled coarse aggregate is obviously lower than that of JD-HBRAC, and even the shrinkage of EKL-HBRAC is comparable to that of natural concrete under the condition of a low replacement rate of recycled aggregate. In addition, the cementitious material content also has a greater influence on the drying shrinkage of recycled concrete. Compared with the cementitious material content of $300 \mathrm{~kg} / \mathrm{m}^{3}$, the $180 \mathrm{~d}$ shrinkage of HBRAC with the cementitious material content of $400 \mathrm{~kg} / \mathrm{m}^{3}$ and $500 \mathrm{~kg} / \mathrm{m}^{3}$ increased by about $17.6 \% \sim 20.1 \%$ and $32.7 \% \sim 37.6 \%$, respectively.

(4) Compared with ordinary Portland cement-based recycled aggregate concrete, high belite sulphoaluminate cement-based recycled aggregate concrete not only has early strength and quick hardening, but also keeps higher compressive strength in the middle and late stages, and has excellent drying shrinkage resistance, which can ensure that the shrinkage rate can be reduced to more than $75 \%$.

Author Contributions: Methodology, formal analysis, data course, and writing-original draft, Z.Y.; investigation and writing-review and editing, Y.G.; resources and visualization, G.Y.; supervision and conception, Z.H.; validation, C.L.; project administration and funding acquisition, Q.L.; software, L.W. All authors have read and agreed to the published version of the manuscript.

Funding: This research was funded by the National Natural Science Foundation of China, grant number 51878366, 51808310, 51978353, and 52078261, the Natural Science Foundation of Shandong Province, China, grant number ZR2019PEE007 and ZR2020ME036, the Qingdao Municipal Government Procurement Project, grant number ZFCG2019000063, and the Qingdao Science and Technology Demonstration and Guidance Project (20-3-4-10-nsh).

Institutional Review Board Statement: Not applicable.

Informed Consent Statement: Not applicable. 
Data Availability Statement: Since the experiment was completed with the support of Qingdao Agricultural University and Qingdao University of Technology, the data used to support the results of this study are available from the responsible person and the author upon request.

Conflicts of Interest: The authors declare no conflict of interest.

\begin{tabular}{|c|c|}
\hline RCA & recycled coarse aggregate \\
\hline JD-RCA & simple crushing recycled coarse aggregate \\
\hline KL-RCA & one-time particle-shaping recycled coarse aggregate \\
\hline EKL-RCA & two-time particle-shaping recycled coarse aggregate \\
\hline HBSAC & high belite sulphoaluminate cement \\
\hline OPC & ordinary Portland cement \\
\hline RAC & recycled aggregate concrete \\
\hline HBRAC & high belite sulphoaluminate cement-based recycled aggregate concrete \\
\hline OPRAC & ordinary Portland cement-based recycled aggregate concrete \\
\hline JD-HBRAC & $\begin{array}{l}\text { high belite sulphoaluminate cement-based recycled concrete with simple } \\
\text { crushed recycled coarse aggregate }\end{array}$ \\
\hline KL-HBRAC & $\begin{array}{l}\text { high belite sulphoaluminate cement-based recycled concrete with one-time } \\
\text { particle-shaping recycled coarse aggregate }\end{array}$ \\
\hline EKL-HBRAC & $\begin{array}{l}\text { high belite sulphoaluminate cement-based recycled concrete with two-time } \\
\text { particle-shaping recycled coarse aggregate }\end{array}$ \\
\hline
\end{tabular}

\section{References}

1. Esin, T.; Cosgun, N. A study conducted to reduce construction waste generation in Turkey. Build. Environ. 2007, 42, 1667-1674. [CrossRef]

2. Wang, J.; Yuan, H.; Kang, X.; Lu, W. Critical success factors for on-site sorting of construction waste: A China study. Resour. Conserv. Recycl. 2010, 54, 931-936. [CrossRef]

3. Wu, Z.; Zhang, X.; Wu, M. Mitigating construction dust pollution: State of the art and the way forward. J. Clean. Prod. 2016, 112, 1658-1666. [CrossRef]

4. Cheriyan, D.; Choi, J.H. A review of research on particulate matter pollution in the construction industry. J. Clean. Prod. 2020, 254, 120077. [CrossRef]

5. $\quad$ Begum, R.A.; Satari, S.K.; Pereira, J.J. Waste generation and recycling: Comparison of conventional and industrialized building systems. Am. J. Environ. Sci. 2010, 6, 383. [CrossRef]

6. Cho, Y.H.; Yun, T.; Kim, I.T.; Choi, N.R. The application of recycled concrete aggregate (RCA) for hot mix asphalt (HMA) base layer aggregate. KSCE J. Civ. Eng. 2011, 15, 473-478. [CrossRef]

7. Yoda, K.; Shintani, A. Building application of recycled aggregate concrete for upper-ground structural elements. Constr. Build. Mater. 2014, 67, 379-385. [CrossRef]

8. Eguchi, K.; Teranishi, K.; Nakagome, A.; Kishimoto, H.; Shinozaki, K.; Narikawa, M. Application of recycled coarse aggregate by mixture to concrete construction. Constr. Build. Mater. 2007, 21, 1542-1551. [CrossRef]

9. Cai, X.; Wu, K.; Huang, W.; Yu, J.; Yu, H. Application of recycled concrete aggregates and crushed bricks on permeable concrete road base. Road Mater. Pavement Des. 2021, 22, 2181-2196. [CrossRef]

10. Malesev, M.; Radonjanin, V.; Marinkovic, S. Recycled concrete as aggregate for structural concrete production. Sustainability 2010, 2, 1204-1225. [CrossRef]

11. Li, J.; Xiao, H.; Zhou, Y. Influence of coating recycled aggregate surface with pozzolanic powder on properties of recycled aggregate concrete. Constr. Build. Mater. 2009, 23, 1287-1291. [CrossRef]

12. Singh, L.P.; Bisht, V.; Aswathy, M.S.; Chaurasia, L.; Gupta, S. Studies on performance enhancement of recycled aggregate by incorporating bio and nano materials. Constr. Build. Mater. 2018, 181, 217-226. [CrossRef]

13. Zeng, W.; Zhao, Y.; Poon, C.S.; Feng, Z.; Lu, Z.; Shah, S.P. Using microbial carbonate precipitation to improve the properties of recycled aggregate. Constr. Build. Mater. 2019, 228, 116743. [CrossRef]

14. Zhan, B.; Poon, C.S.; Liu, Q.; Kou, S.; Shi, C. Experimental study on CO2 curing for enhancement of recycled aggregate properties. Constr. Build. Mater. 2014, 67, 3-7. [CrossRef]

15. Liu, S.; Shen, P.; Xuan, D.; Li, L.; Sojobi, A.; Zhan, B.; Poon, C.S. A comparison of liquid-solid and gas-solid accelerated carbonation for enhancement of recycled concrete aggregate. Cem. Concr. Compos. 2021, 118, 103988. [CrossRef]

16. Shi, C.; Li, Y.; Zhang, J.; Li, W.; Chong, L.; Xie, Z. Performance enhancement of recycled concrete aggregate-A review. J. Clean. Prod. 2016, 112, 466-472. [CrossRef]

17. Kim, J.H.; Sung, J.H.; Jeon, C.S.; Lee, S.H.; Kim, H.S. A study on the properties of recycled aggregate concrete and its production facilities. Appl. Sci. 2019, 9, 1935. [CrossRef] 
18. Liu, Y.; Pang, S.; Wang, L.C. Modification of recycled aggreate and recycled concrete. Recycl. Res. 2005, 1, 33-39.

19. Ryu, J.S. Improvement on strength and impermeability of recycled concrete made from crushed concrete coarse aggregate. J. Mater. Sci. Lett. 2002, 21, 1565-1567. [CrossRef]

20. Kim, Y.; Hanif, A.; Kazmi, S.M.; Munir, M.J.; Park, C. Properties enhancement of recycled aggregate concrete through pretreatment of coarse aggregates-Comparative assessment of assorted techniques. J. Clean. Prod. 2018, 191, 339-349. [CrossRef]

21. Zhang, H.; Xu, X.; Su, S.; Zeng, W. To improve the resistance of recycled aggregate concrete (RAC) to the internal steel corrosion by the pre-treatment of aggregate. Constr. Build. Mater. 2021, 306, 124911. [CrossRef]

22. Zhang, H.; Ji, T.; Liu, H.; Su, S. Modifying recycled aggregate concrete by aggregate surface treatment using sulphoaluminate cement and basalt powder. Constr. Build. Mater. 2018, 192, 526-537. [CrossRef]

23. Wang, J.; Zhang, J.; Cao, D.; Dang, H.; Ding, B. Comparison of recycled aggregate treatment methods on the performance for recycled concrete. Constr. Build. Mater. 2020, 234, 117366. [CrossRef]

24. LI, Q.; ZHU, Y.; Gao, S. Study on the Preparation Technique and Quality Evaluation Method of High Quality Recycled Aggregate. J. Qingdao Technol. Univ. 2009, 30, 1-4.

25. Medina, C.; Zhu, W.; Howind, T.; de Rojas, M.I.S.; Frlas, M. Influence of mixed recycled aggregate on the physical-mechanical properties of recycled concrete. J. Clean. Prod. 2014, 68, 216-225. [CrossRef]

26. Zhou, C.; Chen, Z. Mechanical properties of recycled concrete made with different types of coarse aggregate. Constr. Build. Mater. 2017, 134, 497-506. [CrossRef]

27. Bui, N.K.; Satomi, T.; Takahashi, H. Improvement of mechanical properties of recycled aggregate concrete basing on a new combination method between recycled aggregate and natural aggregate. Constr. Build. Mater. 2017, 148, 376-385. [CrossRef]

28. Xie, T.; Gholampour, A.; Ozbakkaloglu, T. Toward the development of sustainable concretes with recycled concrete aggregates: Comprehensive review of studies on mechanical properties. J. Mater. Civ. Eng. 2018, 30, 04018211. [CrossRef]

29. Rodrlguez-Robles, D.; Garcla-Gonzalez, J.; Juan-Valdes, A.; Moran-del Pozo, J.M.; Guerra-Romero, M.I. Effect of mixed recycled aggregates on mechanical properties of recycled concrete. Mag. Concr. Res. 2015, 67, 247-256. [CrossRef]

30. Ismail, S.; Ramli, M. Mechanical strength and drying shrinkage properties of concrete containing treated coarse recycled concrete aggregates. Constr. Build. Mater. 2014, 68, 726-739. [CrossRef]

31. Limbachiya, M.C.; Leelawat, T.; Dhir, R.K. Use of recycled concrete aggregate in high-strength concrete. Mater. Struct. 2000, 33, 574-580. [CrossRef]

32. Gonzalez-Corominas, A.; Etxeberria, M. Effects of using recycled concrete aggregates on the shrinkage of high performance concrete. Constr. Build. Mater. 2016, 115, 32-41. [CrossRef]

33. Yang, S. Effect of different types of recycled concrete aggregates on equivalent concrete strength and drying shrinkage properties. Appl. Sci. 2018, 8, 2190. [CrossRef]

34. Mao, Y.; Liu, J.; Shi, C. Autogenous shrinkage and drying shrinkage of recycled aggregate concrete: A review. J. Clean. Prod. 2021, 295, 126435. [CrossRef]

35. Zhang, H.; Wang, Y.; Lehman, D.E.; Geng, Y.; Kuder, K. Time-dependent drying shrinkage model for concrete with coarse and fine recycled aggregate. Cem. Concr. Compos. 2020, 105, 103426. [CrossRef]

36. Hu, H.B.; He, Z.H.; Shi, J.Y.; Liang, C.F.; Shibro, T.G.; Liu, B.J.; Yang, S.Y. Mechanical properties, drying shrinkage, and nanoscale characteristics of concrete prepared with zeolite powder pre-coated recycled aggregate. J. Clean. Prod. 2021, 319, 128710. [CrossRef]

37. Domingo, C.A.; Lazaro, C.; Lopez-Gayarre, F.; Serrano-Lopez, M.A.; Serna, P.; Castano-Tabares, J.O. Creep and shrinkage of recycled aggregate concrete. Constr. Build. Mater. 2009, 23, 2545-2553. [CrossRef]

38. Kou, S.C.; Poon, C.S.; Agrela, F. Comparisons of natural and recycled aggregate concretes prepared with the addition of different mineral admixtures. Cem. Concr. Compos. 2011, 33, 788-795. [CrossRef]

39. He, Z.H.; Hu, H.B.; Casanova, I.; Liang, C.F.; Du, S.G. Effect of shrinkage reducing admixture on creep of recycled aggregate concrete. Constr. Build. Mater. 2020, 254, 119312. [CrossRef]

40. Liu, C.; Luo, J.; Li, Q.; Gao, S.; Su, D.; Zhang, J.; Chen, S. Calcination of green high-belite sulphoaluminate cement (GHSC) and performance optimizations of GHSC-based foamed concrete. Mater. Des. 2019, 182, 107986. [CrossRef]

41. Su, D.; Yue, G.; Li, Q.; Guo, Y.; Gao, S.; Wang, L. Research on the preparation and properties of high belite sulphoaluminate cement (HBSAC) based on various industrial solid wastes. Materials 2019, 12, 1510. [CrossRef] [PubMed]

42. Atiq, A.; Niu, S.; Pengju, H. Study on Development of High Belite Sulphoaluminate Cement-Based Grouting Material. N. Am. Acad. Res. J. 2021, 4, 334-344.

43. Wang, L.; Ma, H.; Li, Z.; Ma, G.; Guan, J. Cementitious composites blending with high belite sulfoaluminate and medium-heat Portland cements for largescale 3D printing. Addit. Manuf. 2021, 46, 102189. [CrossRef]

44. Gao, Y.; Li, Z.; Zhang, J.; Zhang, Q.; Wang, Y. Synergistic use of industrial solid wastes to prepare belite-rich sulphoaluminate cement and its feasibility use in repairing materials. Constr. Build. Mater. 2020, 264, 120201. [CrossRef]

45. Ge, Z.; Yuan, H.; Sun, R.; Zhang, H.; Wang, W.; Qi, H. Use of green calcium sulphoaluminate cement to prepare foamed concrete for road embankment: A feasibility study. Constr. Build. Mater. 2020, 237, 117791. [CrossRef] 